\title{
Physician Burnout and Occupational Stress: An inconvenient truth with unintended consequences
}

\author{
Michael R. Privitera*1, Alan H. Rosenstein ${ }^{2}$, Franziska Plessow ${ }^{3}$, Tara M. LoCastro ${ }^{4}$ \\ ${ }^{1}$ University of Rochester Medical Center, Rochester, United States \\ ${ }^{2}$ Health Care Management, Physician Wellness Services, San Francisco, United States \\ ${ }^{3}$ Berenson-Allen Center for Noninvasive Brain Stimulation, Department of Neurology, Beth Israel Deaconess Medical Center, \\ Harvard Medical School, Boston, United States \\ ${ }^{4}$ Principal, Galica Healthcare, Rochester, United States
}

Received: September 26, 2014

Accepted: November 27, 2014 Online Published: December 4, 2014

DOI: $10.5430 /$ jha.v4n1p27

URL: http://dx.doi.org/10.5430/jha.v4n1p27

\begin{abstract}
Healthcare providers and staff are the proximal source of quality of care provided to patients. Today's world of health care reform and other value-based initiatives have added new levels of significant complexity to health care delivery. This cumulative chronic high-level stress is imposed by multiple regulatory, insurance, federal, and state forces that do not coordinate well with one another resulting in disparate, conflictual, or confusing mandates. Each have authoritative capital. Together they have potential to affect healthcare workers on a personal, physical, emotional and cognitive level which in turn adversely affects care relationships and quality of patient care. We need to be concerned about the effect that this enormous occupational stress has on them as individuals and how it impacts the care provided. Physician shortages exist and are projected to get worse. There is a high burnout rate in current physicians. Some are retiring early, leaving medicine, or worse dying of suicide from job related stress. Mechanisms of this negative effect of stress and Burnout on providers, institutions and healthcare quality are discussed. The aim of this paper is to provide an overview of current state of knowledge merging information from various fields on this issue. Areas that require action are identified and possible solutions are offered.
\end{abstract}

Key Words: Stress and burnout, Workforce issues, Public health, Organization and delivery of care, Physicians, Medicine/Clinical issues

\section{Thesis and background}

Healthcare providers and staff are the proximal reason for the quality of care provided to patients. What effect does increasing high-level and chronic occupational stress on providers and staff imposed from multiple uncoordinated sources have on them personally and ultimately the patients they serve? Has physician burnout been multiplied and yet underappreciated in impact?
We currently have a time-challenged, overburdened, and burned-out healthcare workforce. There exists no single group to oversee the reasonableness of the total human burden on staff and providers placed by regulatory, certification, national, state, and industry sources. There is no agency or mandate that ensures coordination and collaboration of these independent forces to be cognizant of total logistical impact. $46 \%$ of surveyed physicians reported burnout, with even higher rates in front line doctors (Fam-

\footnotetext{
*Correspondence: Michael R. Privitera, MD, MS; Email: michael_privitera@urmc.rochester.edu; Address: University of Rochester Medical Center, Patient and Family Centered Care Clinician Training Team and Workplace Safety Committee URMC, 300 Crittenden Blvd, Rochester NY, United States.
} 
ily Medicine, General Internal Medicine, and Emergency Medicine). ${ }^{[1]}$ Suicide rate for physicians is higher than the average suicide rate in the US. ${ }^{[2]} \mathrm{MD}$ early retirement or leaving medicine from economic, healthcare reform regulatory pressures and burnout. ${ }^{[3]}$ Physician shortages anticipated in 2014: Without Affordable Care (ACA)/with ACA, $30,200 / 58,000^{[4]}$ Request is in Congress to increase med- ical student slots with hope to increase residency slots as well. $^{[5]}$ Many factors that will be discussed indicate that the healthcare workforce and the public are now at physical, emotional, and financial risk by the uncoordinated cumulative over-expectation of cognitive workload imposed on providers and staff ${ }^{[6,7]}$ (see Figure 1).
Figure 1: Uncoordinated incremental stresses

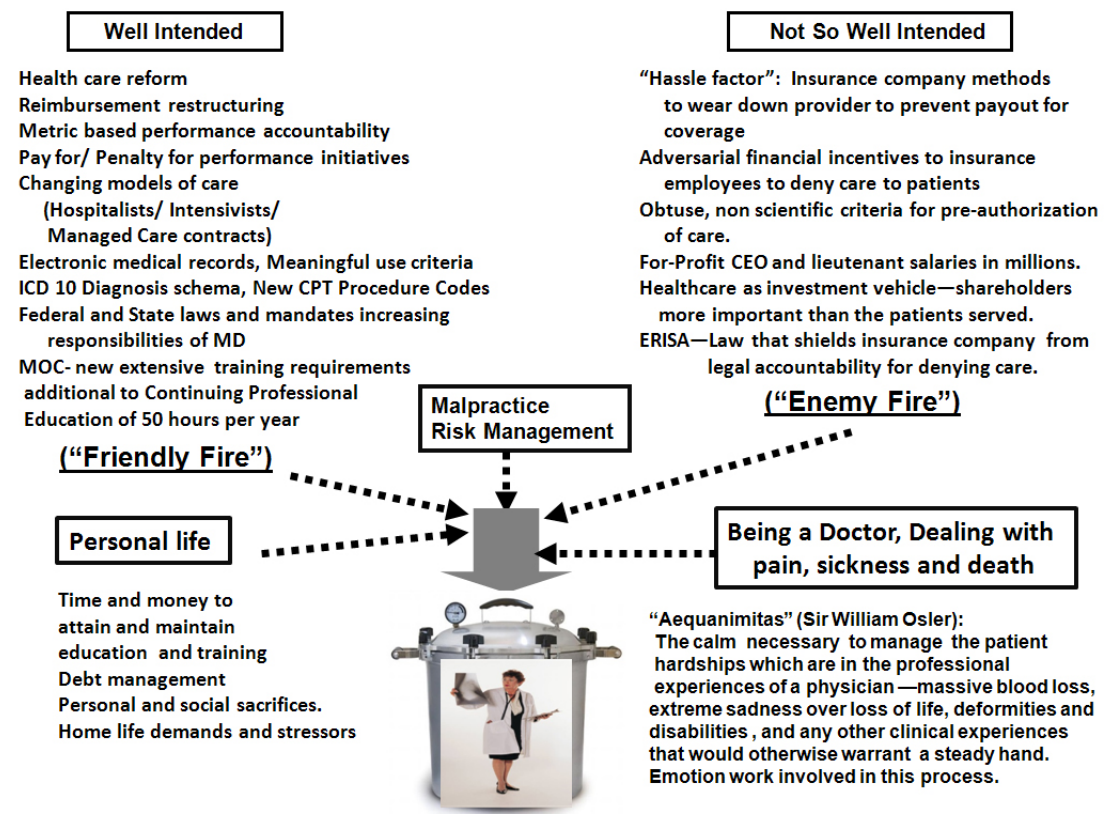

Cognitive workload is known to be a risk factor to workers and the people they serve in such professions as airline pilots, air traffic controllers, and nuclear power workers. Yet, there is little attention in the area of healthcare delivery. Additionally, healthcare providers deal with illness and death and must suppress emotional responses and other emotional work. This places them at more risk than the above professions to become overwhelmed and impaired from excessive cognitive load. Providers and staff are at their core an altruistic profession, tend to be high achievers, and are mentored in self-effacement. As a result, they are a high-risk group to reject normal checks and balances of self-care and continue to overwork especially when demands come from authoritative sources.

The aim of this paper is to provide an overview of the current state of knowledge, merging various fields in order to identify areas that require action together with proposing possible solutions.

\section{Work stress and expected duties - rele- vant proof}

\subsection{Occupational stress}

The National Institute for Occupational Safety and Health defines Occupational Stress as "the harmful physical and emotional responses that occur when the requirements of the job do not match the capabilities, resources, or needs of the worker". ${ }^{8]}$ The concept of occupational stress is often confused with challenge, but these concepts are not the same. Challenge energizes us psychologically and physically, and it motivates us to learn new skills and master our jobs.

Chronic, cumulative and incremental stress needs to be differentiated from acute temporary situations of high stress that are expected parts of the work done by physicians and nurses. Stress has a subjective experience and physiologic component. On a physiologic level, stress is characterized by activation of two major stress axes: The sympathetic nervous system which puts out higher levels of epinephrine and norepinephrine; and the hypothalamic-pituitary-adrenal (HPA) axis. The latter results in elevated levels of glucocorticoids, primarily cortisol. Frequent/constant activation of these axes has been well documented to induce health problems for the individual and will deteriorate the quality of decision ability which can result in worse decisions and sub-optimal solutions.

Stress has been documented to be increasing in all full-time employed individuals by 31\% from 1983 till 2009 in the U.S. using the Perceived Stress Scale. ${ }^{[9]}$ Sixty-three percent of physicians surveyed in 2012 reported that they were more stressed than three years prior, and $34.3 \%$ reported that they were much more stressed than three years prior. ${ }^{[10]}$ 


\subsection{Burnout and its causes}

\section{Burnout can be defined on several levels}

- Exhaustion: Physical and Emotional. Downward spiral, even after attempting to rest.

- Depersonalization: Dysfunctional coping mechanism. Keeping your patients at a distance to not drain you more: Cynicism, sarcasm, compassion fatiguenothing left to give.

- Lack of efficacy: What is the use? What is the purpose? Work is subpar, feel like not making a difference, work has no purpose. ${ }^{[11]}$

Burnout is the polar opposite of engagement, when defined by vigor, dedication and absorption in your work. ${ }^{[12]}$

Stress and burnout can be related to a number of different factors. Much of this relates to individual core values, attitudes, expectations, and behaviors gained through genetic makeup and life experiences (see Table 1). Deep seated internal perspective attitudes and values related to age and generation, gender, culture and ethnicity, religious and spiritual values, and other early life experiences help shape one's personality. A second contributing factor are the more adult experiences shaping values and attitudes influenced by medical training, debt obligations, and pressures from the current work and home environment.

Table 1: Factors affecting physician behavior

\begin{tabular}{ll}
\hline Internal & External \\
\hline Age (generation) & Training \\
Gender & Debt \\
Culture \& ethnicity & Environment \\
Geographics/Life experiences & Revenues \\
Personality & Expectations \\
\hline
\end{tabular}

Note. Internal: Age and generational values, gender differences, culture, ethnic, and religious beliefs, geographic contributions (East, West, South, Midwest), and life experiences all lead to a person's "personality" which affects attitudes, values, and behaviors. Externals: Training, debt, new environmental pressures (reform, accountability, economics), and thwarted expectations all lead to increasing levels of dissatisfaction, disillusion, frustration, anger, stress, and burnout.

In a study on Physician Burnout by Rosenstein, the three top external factors given as contributing to their stress included the overall economy (52\%), health care reform (46\%), and Centers for Medicare and Medicaid Services' (CMS) policies $(41 \%)$. The top three work-related factors contributing to stress were paperwork and administrative demands $(40 \%)$, too many hours of work $(33 \%)$, and on-call schedules and expectations $(26 \%){ }^{[13]}$

\subsection{Mechanisms of impact, medical decision mak- ing, and executive functions}

Human compliance with legitimized authority tends to be high despite distress that occurs when authority requires you to do something that you may feel is intrinsically

Published by Sciedu Press wrong. ${ }^{[14]}$ Physicians are trained to use what they have learned for medical decision making (MDM). Prefrontal cortex (PFC) is the part of the physician's brain that (together with widespread neuronal networks) is responsible for executive function (EF). EF weighs the multiple factors at hand to make the best diagnosis and treatment plan and is a limited resource. It includes the ability to manage time, attention, switch focus, plan and organize, remember details, curb inappropriate behavior and speech, and integrates past experience (e.g. medical training and experiences) with present needed action to practice medicine of the highest order. The PFC is a collection of interconnected cortical areas that send and receive projections from virtually all brain cortical sensory systems, motor systems, and many other brain structures. Hence, the PFC is important when "top-down" processing is needed to decide what is relevant and what distraction from the intended action. ${ }^{[15]}$

PFC is the most evolved brain region and sub serves our highest-order cognitive abilities. Unfortunately, it is also the brain region that is most sensitive to the detrimental effects of stress exposure. Even quite mild acute uncontrollable stress can cause a rapid and dramatic loss of prefrontal cognitive abilities, and more prolonged stress exposure causes architectural changes in prefrontal nerve cells. ${ }^{[16-23]}$ This constant prioritization processing induced by uncoordinated mandates and subsequent diminished attentional resources available then increases "goal shielding" that attempts to help the doctor filter out other factors and get overly narrow in focus.

Over-focus on specifically allocated task-relevant processing (for example, making sure all the Meaningful Use in the electronic record are noted as "marked as reviewed" by properly clicking the appropriate buttons), then detract from cognitive flexibility needed in the clinical moment with the patient needed to weigh factors at hand. Habit memory then predominates over the cognitive flexible memory ${ }^{[19]}$ that would have been used to examine factors in more accurate diagnosis, more comprehensive and effective care planning, as well as the emotional availability to the patient and family.

MDM requires efficient and successful decisions and actions, frequently in situations of fast-changing environmental demands. Cognitive control processes allow individuals to flexibly adjust their thoughts and behaviors in accordance to their internal goals and contextual requirements. Acute stress however has been shown to reduce this flexibility. ${ }^{[19,23-25]}$ Furthermore, it results in more interference between tasks that are performed at the same time, limiting the individual's multitasking abilities. ${ }^{[26]}$

Cognitive processing capacity of the human mind is limited by the cognitive load put on these capacities. Intrinsic $v s$. extraneous $v s$. germane cognitive load are the factors involved in best decision making. ${ }^{[27]}$ Intrinsic load refers to 
the inherent difficulty of the mental task. Extraneous load refers to a burden of unnecessary information that uses up cognitive processing. Germane load refers to an organized pattern of thought that helps in efficient learning and mental tasks. Excessive extraneous load will deplete EF away from the ability to make good medical decisions. ${ }^{[28]}$

Cognitive dissonance and occupational stress occurs in physicians when practice control has to be relinquished to entities that are more remote, faceless, and who do not allow feedback from direct care-providing physicians who see the negative impact and burden of the authoritative order. ${ }^{[29]}$

\section{Work and home environment synergistic factors}

\subsection{Recent potential contributory factors and neu- rocognitive impact}

Adding more mandates, regulations, laws or complex policies to an overworked workforce is not a harmless endeavor, especially if there is no clear scientific evidence that quality of care will be improved. Several recent studies show that the Value Based Pay for Performance Initiatives have not sustained long term improvements in care. ${ }^{[30]}$ The strategy used a government financial muscle approach to reward doctors for positive outcomes not procedures. To some decision-makers, this initiative looked intuitively appealing but did not work out as well as hoped. ${ }^{[31]}$ Tailoring pay-forperformance programs to hospital's specific situation may have a greater effect on healthcare quality ${ }^{[32]}$ and this later approach would have more individual hospital collaboration with payers instead of adopting a mandatory one size fits all.

Meaningful Use (MU) is the CMS initiative in electronic health documentation meant to electronically capture provider behaviors, by clicking buttons that you have completed CMS prescribed tasks. High compliance with the prescribed tasks means you qualify for federal money to offset electronic record expenditure. Meaningful Use was recently found to not be correlated with performance on clinical quality measures. ${ }^{[33]}$ Rolled out as purely a financial incentive program, the fact that estimated $75 \%$ of US physicians are employed by hospital systems ${ }^{[34]}$ this initiative is mandatory for most US physicians.

A new set of current procedural terminology (CPT) codes was released from the American Medical Association and is meant to improve our procedural coding system. International Classification of Diseases-10 (ICD-10) is a new diagnostic schema. The Federation of State Medical Boards (FSMB) is working to mandate new maintenance of certification (MOC) and maintenance of licensure (MOL) requirements. These requirements are additional to the current Category 1 Continuing Medical Education (CME) requirement of 50 hours a year as well as of every 10 year Board Certification examination that requires extensive study and are expenses placed on providers. There is no clear scientific evidence that MOC improves quality of care at the point of clinical service. ${ }^{[35]}$

Newer Electronic Health Record (EHR) systems prioritize capturing as many MU as possible to obtain federal money set aside to reimburse for EHR expenditure. The design trade-off for MU capture priority has led to poorer clinical workflow design, actually interfering with and obstructing normal clinical operations. Daily operational impairment to clinical workflow creates chronic frustration and distress for providers and staff which does not eliminate with time and familiarity with the EHR program. This cognitive strain depletes executive function available which increases the risk of errors. Increased documentation time has cut into productivity, and lengthened the work time in a day further affecting work/life balance.

Inadequate risk/benefit analysis occurs if the authoritative mandate source does not account for or coordinate with other sources of mandates, regulations, and laws imposed on physicians. Otherwise it is impossible to reasonably assess total impact and potential unintended consequences of the initiative. These uncoordinated efforts have unknowingly caused reckless endangerment of staff and patients, and the interventions in summation become counterproductive to their intended purpose.

Many administrative and regulatory influences begin with good intentions ("friendly fire"), and may include the additive effect of too many uncoordinated "quality" measures and reactive "corrective" policies to events. In summation they may cumulatively paralyze care. Some influences have not-so-good intentions and are purely financial in motivation ("enemy fire"). Examples include purposeful hassles to patients and providers to lessen payments for care that create unreasonably enormous profits. These factors both add up to feeling under siege and are added non-work life stress and daily work stress of being a physician. Being compassionate while dealing with pain, suffering, illness, injury, blood loss, death, and distressed families ${ }^{[21]}$ is what physicians expected when going to medical school. The additional tsunami of insidious stressors they did not expect nor have they been prepared for.

\subsection{Non-work life and feeling trapped}

Physicians have gone to school a minimum of 21 years. The Association of American Medical Colleges (AAMC) reports the median four-year cost for medical school for the class of 2013: $\$ 278,455$ for private school and $\$ 207,868$ for public ones. ${ }^{[36]}$ Thirty-six percent of those graduating from medical school have debt of over $\$ 200,000,22 \%$ owe $\$ 100 \mathrm{~K}-200 \mathrm{~K}, 6 \% \$ 50-100 \mathrm{~K}, 7 \%<\$ 7 \mathrm{~K}$, and only $25 \%$ have no debt. ${ }^{[37,38]}$ After this much time and financial commitment has been made to become a physician, they are substantially trapped in their profession. Having a daily sense 
that your work life is under siege from innumerable outside sources creates more demoralization and stress than is currently appreciated. The more outside influences that mandate activity that is beyond their control to influence the more the PFC degenerates in function. Satisfying these mandates is often relegated to "discretionary time" that is not paid for by the employer. This chronic home-life time conflict greatly increases unnecessary stress on them which negatively spills over to their family relationships.

\subsection{Psychology of medical training}

The psychology of medical training added to pre-existing altruistic characteristics of individuals can cause difficulty in being aware how stressed the physician actually is. Pushing oneself beyond usual human abilities is the cultural norm in pre-med, medical school, and residency. This cultural training makes individuals less likely to realize the unreasonable level of expectation that incrementally has accumulated. Drummond has outlined a number of characteristics of physicians that predispose them to burnout with the clandestine psychology of medical training: Be a workaholic, superhero, emotion-free, Lone Ranger, perfectionist, show self-effacement (how you feel does not matter, the patient is always first), and do not ask for help. ${ }^{[39]}$

\subsection{Mechanisms of impact at individual, institution, and patient interface}

When work demands exceed a maximal level, human functioning capability is negatively affected. ${ }^{[40]}$ Plotting performance versus stress arousal, there is a range from "comfort zone" and ability to "stretch" to take on more duties. After the "hump" in an average reasonable individual, there is a degeneration of the ability to cognitively function, less compassion, irritability, less ability to listen the patients, and medical, physiologic stress-related illnesses occur as does disability and death (see Figure 2). Chronic distress and hyper-stress situations have been highly correlated to lack of control of one's life. ${ }^{[41]}$

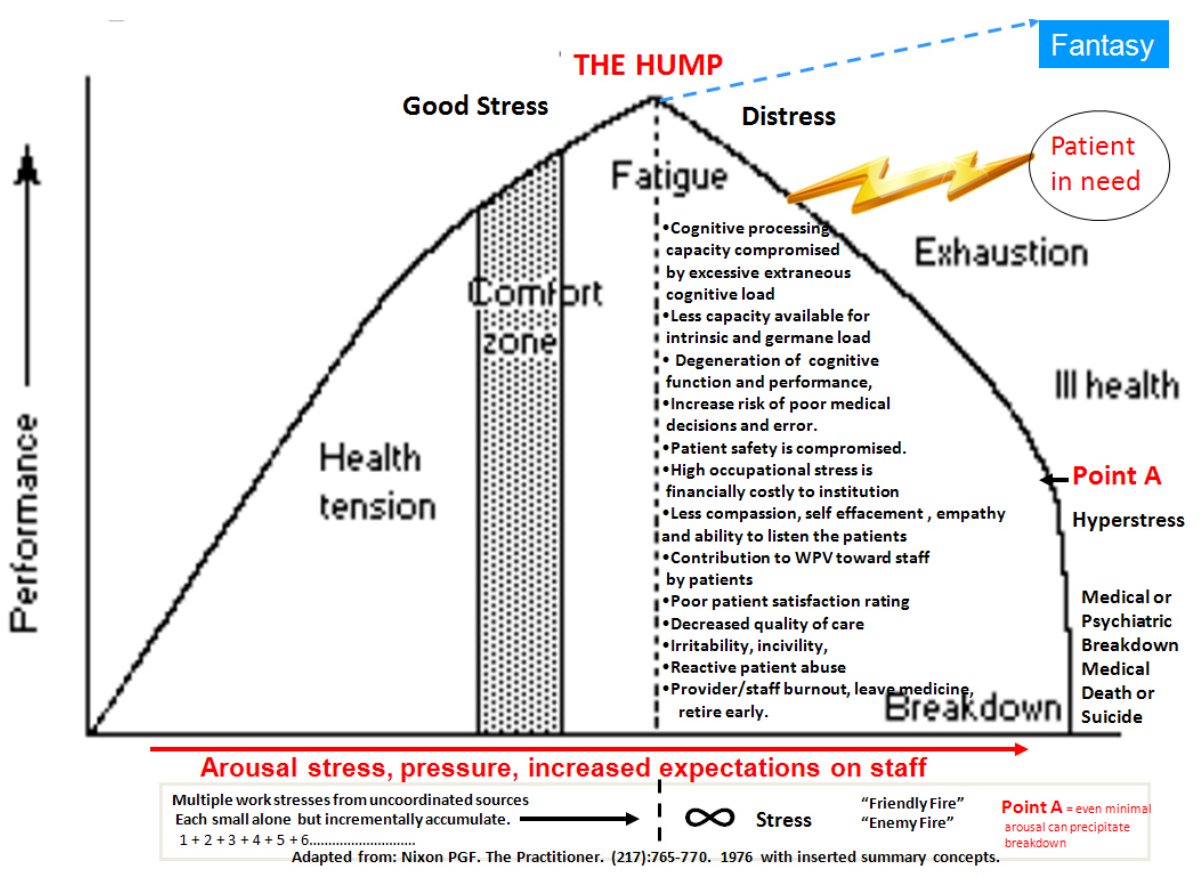

Figure 2: Human function curve in average provider/staff

\section{Strategic business drivers}

\subsection{Overview}

Some may ask whether there is a need for a business case to reduce Burnout. Isn't there a moral responsibility to reduce physician burnout? The business of healthcare has evolved substantially with more individuals as investors external to the field of medicine. Even the most ethical employers and decision makers will be helped by making the business case for reducing burnout and improving healthy work environments for providers. ${ }^{[42]}$ Effects of stress and burnout have significant impact on the business of healthcare. Major impact from physician burnout includes include lower job sat- isfaction, desire to work fewer hours, and desire to retire early or to leave the practice for another career. Addressing the impact of stress and/or burnout on providers is a business imperative that warrants attention. ${ }^{[43]}$

\subsection{Financial issues}

Excessive workplace stress has direct effect on healthcare workers health, ${ }^{[4-49]}$ has financial impact on the institution in which they work ${ }^{[50,51]}$ and the cognitive performance of the provider or staff, especially if adverse conditions persist and no clear end-point to the stressful circumstances exist. Occupational stress accumulation leads to diminished occupational performance. ${ }^{[51-55]}$ Conversely, positive organiza- 
tional environments, supportive to those doing the work at hand, lead to increase performance and financial improvements. ${ }^{[56,57]}$

High burnout is associated with a higher personal healthcare expenditure compared with low burnout physicians, per member. Stakeholders should therefore address burnout to reduce expenditure and promote health. ${ }^{[47]}$

Patients of physicians with high-exhaustion and high depersonalization had significantly lower satisfaction scores, compared with patients of physicians with low-exhaustion and low-depersonalization, respectively. ${ }^{[58]}$ The leading cause of short-term and long-term disability in 2005 was mental health issues, including stress. ${ }^{[59]}$ Burnout is associated with increased rates of medical errors, malpractice risk, physician and staff turnover, and increased start up and ramp up costs. ${ }^{[48]}$ Physicians who suffer from stress and burnout can present patient safety risks such as difficulty making decisions, communicating effectively with others, irritability and conflict which can translate into costly medical errors.

\subsection{Organizational profile}

The healthcare employer that becomes active in reducing burnout and improving work environmental health becomes the "employer of choice" - demonstrating corporate social responsibility to the community, staff and patients, increasing added value to stakeholders and shareholders. Chronic unaddressed disruptive behavior and lower morale resulting from stress and/or burnout makes physician engagement especially challenging. These factors translate through the organization with ultimately adverse interfaces with colleagues and patients. Organizations who promote safety and quality among other core values must confront and effectively address work related causes for stress and burnout using both preventive and mitigation measures. ${ }^{[43]}$ Progressive organizations will proactively intervene by systematically providing organizational sponsored initiatives to support the unique aspects of physician work/life balance. Organizations could improve needed business alignments and coordination to realize their stated missions in healthcare.

\subsection{The legal case}

Healthcare systems need to demonstrate due diligence to physicians, staff, the patient's they serve who are at risk as well as to the stakeholders and shareholders. Case law provides a legal basis to support claims that particular types of stress at certain levels are hazards under health and safety rules. Employers have a duty to abate such foreseeable hazards at the source under general requirements of due diligence. ${ }^{[60]}$

\section{Possible solutions}

Solutions are in the realms of both organizational and individual solutions. Collaboration among, or awareness of na- tional, state and local forces that affect physician work flow and work load is logically necessary to be capable of making an informed risk/benefit assessment of proposed healthcare initiatives.

Healthcare decision-makers must assess potential unintended consequences before mandating new health care initiatives. Those that actually deliver healthcare must be at the design table with system based, local state and national leadership to protect against future unintended negative consequences. Ongoing two-way communication between designers and implementers must be built in to initiatives to allow course corrections if needed. Many current initiatives in healthcare reform are using financial incentives or punitive methods. Alternatives to coercion should be explored in shaping the healthcare system. Positive Behavior Support (PBS) helps improve desired behaviors integrating certain key concepts:

- People don't control others but support others in the change process

- There is a conviction to continually move away from coercion

- It is effective to try to understand the reason for problem behaviors

- Showing dignity and respect is always important

- Applied behavioral science can positively affect valued behaviors in healthcare ${ }^{[61]}$

Hospitals and healthcare systems can reduce stress on physicians by centrally taking on the responsibility to assist physicians with administrative support necessary to streamline the accomplishment of mandates and regulations (reduces extraneous cognitive load). This would require a shift in culture from individual physician responsibility to find the time to comply with mandates needed to do their job, to a healthcare system complying as an organization by assisting its doctors to reduce this administrative extraneous cognitive load. This may not require additional funds, but realignment of responsibilities of support staff. If additional funds are required, they can be justified as investment to reduce physician leakage costs, malpractice costs, healthcare costs, etc.

Leadership commitment to action is key. Gaining back the trust of physicians and staff and sending a message that their welfare is cared about takes consistency, transparency and action. An anonymous survey helps gather needed sitespecific data. Inquiry should include the positives and the stressors of work environment with request for actionable solutions in the setting of limited finances. Results should be shared with physicians and staff in a timely way to rebuild trust through transparency. Data learned from the survey can then be talked about openly in future meetings, encouraging open processes to solutions.

Individual approaches would help those who provide care 
be better able to adjust to the residual stress situation. In this context, systems of education and care have to take an active role in trying to help our physician work force. It should start in medical school and residency training programs. Some of the more progressive schools have begun to introduce courses that address the emotional side of training to enhance self-awareness and early detection of stress responses.

Many organizations have offered support programs on stress management, time management, conflict management, diversity management to help physicians improve their communication and relationship skills that improve overall clinical efficiency and satisfaction. Some organizations utilize Wellness Committees and/or coaching, mindfulness training at primary, secondary and tertiary levels of prevention as well as counseling services to help support physicians better deal with the consequences of stress and burnout. It is important to clearly name the relevant activity as physician burnout prevention workgroup. Burnout can then be seen as the "disease" to be prevented and eliminated. ${ }^{[39]}$

\section{Conclusions}

Multiple regulatory agencies, legislators, insurance companies, certification boards, national, state and private financial and regulatory leadership must become cognizant of their downstream cumulative impact of their initiatives, mandates, regulations and law on the healthcare ecosystem where one change impacts other factors. There are a multitude of systemic factors contributing to the increasing levels of stress and burnout in health care providers that can adversely impact physical, cognitive, and emotional wellbeing. These effects can lead to problems with physician and staff wellbeing, work relationships, career choices, and in some cases negatively impact patient outcomes of care. However, this also presents a rich opportunity for potential positive impact from creative interventions of forwardthinking healthcare systems.

Physicians and other healthcare staff are a precious resource and should be assisted to work at the top of their license and training. We as a system of healthcare need to keep them happy, energized, and healthy so they can do what they want to do in the first place: practice good medicine. ${ }^{[62,63]}$

Physician Burnout is real, multifactorial in cause, currently underdiagnosed, and underappreciated in impact on the healthcare workforce and system. Unfortunately it seems to be relegated to low priority status while numerous healthcare reform and financial initiatives abound. Hence, it may be seen as quite inopportune and inconvenient to numerous uncoordinated business and reform missions if impact effects are not realized.

A clear call to action is indicated. What is the first critical step that can be taken both by the physician and the healthcare system to begin to unwind the perpetuation of this overlooked but malignant issue? What is the best balance between self-efficacy and "healthcare system" as a key enabler for more balance in the direction of better patient care?

Since many forces directly or indirectly influence the life and work of healthcare worker who in turn directly affect the lives of patients, it follows that the Hippocratic Oath taken by physicians: "First, do no harm" must also apply to the individuals, agencies and organizations responsible for the systemic forces on healthcare as well.

\section{References}

[1] Shanafelt TD, et al. Burnout and Satisfaction With Work-Life Balance Among US Physicians Relative to the General US Population Arch Intern Med. 2012; 172(18): 1377-1385. PMid: 22911330. http://dx.doi.org/10.1001/archinternmed.2012.3199

[2] Gold KJ. Available from: http://www.ncbi.nlm.nih .gov/pubmed?term=Gold $\% 20 \mathrm{KJ} \% 5$ BAuthor\%5D\&cauthor =true\&cauthor_uid=23123101. Sen A. Available from: http://www.ncbi.nlm.nih.gov/pubmed?term=Sen\%20A $\% 5 B$ Author\%5D\&cauthor=true\&cauthor_uid $=23123101$. Schwenk TL. Details on suicide among US physicians: data from the National Violent Death Reporting System. Available from: http://www.ncbi.nlm.nih.gov/pubmed?term=Schwenk $\% 2$ 0TL\%5BAuthor\%5D\&cauthor=true\&cauthor_uid=23123101. Gen Hosp Psychiatry. 2012 Nov 1. http://dx.doi.org/10.10 16/j.genhosppsych.2012.08.005

[3] A Tough Time for Physicians. Medical Practice \& Attitude Report. Available from: http://www. jacksonhealthcare.com/. 2012.

[4] Kirch DG, Henderson MK, Dill MJ. Physician Workforce Projections in an Era of Health Care Reform. Annual Review of Medicine.
2012; 63: 435-445. PMid: 21888514. http://dx.doi.org/10. 1146/annurev-med-050310-134634

[5] Association of American Medical Colleges (AAMC) Physician Workforce Policy Recommendations. September 2012.

[6] Bloom SL, Farragher B. "I Gotta Get Out of This Place": Workplace Stress as a Threat to Public Health. (In) Bloom SL \& Farragher B. Destroying Sanctuary. The Crisis in Human Service Delivery Systems. Oxford University Press. NY. Inc. 2011; 61-90.

[7] Batalden PB, Davidoff F. What is "quality improvement" and how can it transform healthcare? Qual. Saf. Health Care. 2007; 16: 2-3. PMid: 17301192. http://dx.doi.org/10.1136/qshc.2006.0 22046

[8] Department of Health and Human Services, Centers for Disease Control and Prevention. National Institute for Occupational Safety and Health. Exposure to Stress. Occupational Hazards in Hospitals. Available from: http://www.cdc.gov/niosh/docs/2008-136 /pdfs/2008-136.pdf

[9] Cohen S, Janicki-Deverts D. Journal of Applied Social Psychology. 2012; 42(6): 1320-1334. http://dx.doi.org/10.1111/j.155 9-1816.2012.00900.x

[10] Available from: http://www.physicianwellnessservices. com/news/stresssurvey . php. Accessed 9-5-14. 
[11] Maslach C, Leiter MP. The Truth About Burnout. How Organizations Cause Personal Stress and What To Do About It. Jossey-Bass Publishers San Francisco. 1997. PMid: 9332965.

[12] Sala nova M, Llorens S. Current State of Research on Burnout and Future Challenges.Papeles del Psicólogo. 2008; 29(1): 59-67.

[13] Rosenstein, A. "Physician Stress and Burnout: What Can We Do?" American College of Physician Executives. November/ December 2012; 38(6): 22-30.

[14] Milgram, S. Behavioral Study of Obedience. Journal of Abnormal and Social Psychology. 1963; 67(4): 371-8. http://dx.doi.org $/ 10.1037 / \mathrm{h} 0040525$

[15] Miller E K, Cohen J D. An integrative theory of prefrontal cortex function. Annual Review of Neuroscience. 2001; 24: 167-202. PMid: 11283309. http://dx.doi.org/10.1146/annurev.neu ro.24.1.167

[16] Arnsten AFT. Stress signaling pathways that impair prefrontal cortex structure and function. Nature. June 2009; 10: 410-422.

[17] Lieberman MD, Eisenberger NI. Pains and Pleasures of Social Life. Science. 13 February 2009; 323: 890-891. PMid: 19213907. http: //dx.doi.org/10.1126/science. 1170008

[18] Rock D. SCARF: a brain-based model for collaborating with and influencing others. Neuroleadership Journal. 2008; 1: 1-9.

[19] Liston C, McEwen BS, Casey BJ. Psychosocial stress reversibly disrupts prefrontal processing and attentional control. PNAS. January 20, 2009; 106(3): 921-917. PMid: 19139412. http://dx.doi.o rg/10.1073/pnas. 0807041106

[20] McManus IC, Winder BC, Gordon D. The causal links between stress and burnout in a longitudinal study of UK doctors. Lancet. 2002; 359: 2089-90. http://dx.doi.org/10.1016/S0140-673 6(02) 08915-8

[21] Zapf D, Seifert C, Schmuttee B, et al. Emotion work and job stressors and their effects on burnout. Psychology and Health. 2001; 16(5): 527-545. PMid: 22804497. http://dx.doi.org/10.1080 108870440108405525

[22] Lawler EK, Hedge A, Pavlovic-Veselinovic S. Cognitive ergonomics, socio-technical systems, and the impact of healthcare information technologies. International Journal of Industrial Ergonomics. 2011; 41: 336-344. http://dx.doi.org/10.1016/j .ergon.2011.02.006

[23] Arnsten AFT. The Biology of Being Frazzled Science. 12 June 1998; 280(5370): 1711-1712

[24] Plessow F, Fischer R, Kirschbaum C, et al. Inflexibly Focused under Stress: Acute Psychosocial Stress Increases Shielding of Action Goals at the Expense of Reduced Cognitive Flexibility with Increasing Time Lag to the Stressor. Journal of Cognitive Neuroscience. 2011; 23(11): 3218-3227. PMid: 21452940. http://dx.doi.org /10.1162/jocn_a_00024

[25] Alexander, J. K, Hillier, A, Smith, R. M, et al. Beta-adrenergic modulation of cognitive flexibility during stress. Journal of Cognitive Neuroscience. 2007; 19: 468-478. PMid: 17335395. http: //dx.doi.org/10.1162/jocn.2007.19.3.468

[26] Plessow, F, Schade, S, Kirschbaum, C, et al. Better not to deal with two tasks at the same time when stressed? Acute psychosocial stress reduces task shielding in dual-task performance. Cognitive, Affective, \& Behavioral Neuroscience. 2012; 12(3): 557-570. PMid: 22684896. http://dx.doi.org/10.3758/s13415-012 -0098-6

[27] Sweller, J. Cognitive load theory, learning difficulty and instructional design. Learning and Instruction. 1994; 4: 295-312. http: //dx.doi.org/10.1016/0959-4752(94)90003-5

[28] Paas F, Renkl A, Sweller J. Cognitive Load Theory: Instructional Implications of the Interaction between Information Structures and Cognitive Architecture. Instructional Science. 2004; 32: 1-8. http: //dx.doi.org/10.1023/B:TRUC.0000021806.17516.d0

[29] Leng S. Who's in control? Why both doctors and patients are frustrated. November 6 2013. Available from: http://www.kevinmd.com/blog/2013/11/control-doc tors-patients-frustrated.html

[30] Jha AK, Joynt KE, Orav EJ, et al. The Long Term Effect of Premier Pay for Performance on Patient Outcomes. N Engl J Med. 2012;
366: 1606-1615. PMid: 22455751. http://dx.doi.org/10.10 56/NEJMsa1112351

[31] Carroll A E. The Problem with 'Pay for Performance' in Medicine. New York Times. July 312014.

[32] Werner RM, Kolstad JT, Stuart EA, et al. The Effect of Pay-ForPerformance in Hospitals: Lessons for Quality Improvement. Health Affairs. April 2011; 30(4): 690-698. PMid: 21471490. http: //dx.doi.org/10.1377/hlthaff.2010.1277

[33] Samal L, Wright A, Healey MJ, et al. Meaningful Use and Quality of Care. JAMA Intern Med. 2014 Jun; 174(6): 997-8. PMid: 24733228. http://dx.doi.org/10.1001/jamainternm ed. 2014.662

[34] Review of Physician Recruiting Incentives. 2012. Available from: http://www.merritthawkins.com/uploadedFiles/M errittHawkins/pdf/mha2012survpreview.pdf

[35] Yasgur BS. Do Recertification demands Waste Doctors' Time and Money. June 4, 2014. Available from: www .medscape.com

[36] Association for American Medical College, Medical School Education debt, Costs and Loan Repayment Fact Card. October 2013. Available from: https://www.aamc.org/download/152968/d ata/

[37] YoungclausJ, Fresne JA. Physician Education Debt and the Cost to Attend Medical School, 2012 Update. Association of American Medical Colleges. February 2013. Available from: https://www. aamc.org/download/328322/data/statedebtreport.pdf

[38] Chen P. Tackling the problem of medical student debt. New York Times. Available from: http://well. blogs .nytimes . com/201 2/12/13/tackling-the-problem-of-medical-student-d ebt/

[39] Drummond D. The Four Horseman of the Physician Burnout Apocalypse. Accessed 7-28-14. Available from: http://www.th ehappymd.com/blog/bid/290379/Physician-Burnout-The -Four-Horsemen-of-the-Physician-Burnout-Apocalypse

[40] Nixon PG. The human function curve. With special reference to cardiovascular disorders: part I. Practitioner. Nov 1976; 217(1301): 765-70. PMid: 995833.

[41] Shermana GD, et al. Leadership is associated with lower levels of stress. PNAS. Available from: www . pnas .org/cgi/doi/10.1073 /pnas.1207042109. 2012. 1-5.

[42] Burton J. The Business Case for a Healthy Workplace IAPA (Industrial Accident Prevention Association). 2008. Available from: www. iapa.ca. Retrieved 8-25-14.

[43] Available from: http://www.cejkasearch.com/?s=burnout. Retrieved 8-29-14.

[44] McEwen BS, Gianaros PJ. Central role of the brain in stress and adaptation: Links to socioeconomic status, health, and disease. Annals of the New York Academy of Sciences. 2010; 1186: 190-222. PMid: 20201874. http://dx.doi.org/10.1111/j.1749-663 2.2009.05331.x

[45] Haines, M M, Stansfeld, S A, Job, R F S, et al. Chronic aircraft noise exposure, stress responses, mental health, and cognitive performance in school children. Psychological Medicine. 2001; 31: 265-277. PMid: 11232914.

[46] Toker S, Melamed S, Berliner S, et al. Burnout and Risk of Coronary Heart Disease: A Prospective Study of 8838 Employees Psychosomatic Medicine. 2012; 74: 840-847. PMid: 23006431. http: //dx.doi.org/10.1097/PSY.0b013e31826c3174

[47] de Beer L, Pienaar J, Rothmann S. Linking employee burnout to medical aid provider expenditure. S Afr Med J. 2013; 103(2): 89-93. PMid: 23374303. http://dx.doi.org/10.7196/samj.6060

[48] Lin Y-W. The causes, consequences, and mediating effects of job burnout among hospital employees in Taiwan. Journal of Hospital Administration. 2013; 2(1): 15-27.

[49] Wolfe IS. The Truth about Employee Stress: Bleeding at the Bottom Line. Business 2 Business, October 2004. Available from: http://www. super-solutions.com/Thetruthaboutwo rkplacestress.asp

[50] Collie D. Workplace Stress: Expensive Stuff. Available from: ht tp://www. emaxhealth.com/38/473.html. July 7, 2004. Retrieved January 15, 2013. 
[51] Hamilton, V, Warburton D. M. Human stress and cognition: An information processing approach. (Eds.) New York: John Wiley \& Sons; 1979.

[52] Hammond, K. R. Judgments under stress. New York; Oxford University Press. 2000.

[53] Hancock, P A, Vasmatzidis, I. Human occupational and performance limits under stress: The thermal environment as a prototypical example. Ergonomics. 1998; 41: 1169-1191. PMid: 9715675. http://dx.doi.org/10.1080/001401398186469

[54] Hancock, P A, Desmond, P A. Stress, workload, and fatigue. (Eds.) NJ: Lawrence Erlbaum Mahwah; 2001.

[55] Hancock, P A, Warm, J S. A dynamic model of stress and sustained attention. Human Factors. 1989; 31: 519-537. PMid: 2625347.

[56] Cotton P, Hart PM. Occupational Wellbeing and Performance: A Review of Organisational Health Research. Australian Psychologist 2003; 38(2): 118-127. http://dx.doi.org/10.1080/0005006 0310001707117

[57] Bowen B, Privitera MR, Bowie V. Reducing Workplace Violence by Creating Healthy Workplace Environments. Journal of Aggression, Conflict and Peace Research. 2011; 3(4): 185-198. http: //dx.doi.org/10.1108/17596591111187710

[58] Anagnostopoulos F, Liolios E, Persefonis G, et al. Physician Burnout and Patient Satisfaction with Consultation in Primary
Health Care Settings: Evidence of Relationships from a one-withmany Design. J Clin Psychol Med Settings. 2012; 19: 401-410. PMid: 22327237. http://dx.doi.org/10.1007/s10880-011 $-9278-8$

[59] Watson Wyatt Worldwide, "Staying @ Work 2005: Making the connection to a healthy organization", page 4. Watson Wyatt Canada, Watson Wyatt "2000 Canadian Staying @ Work" survey. Available from: http: //www. watsonwyatt.com/canada-english/

[60] Shain M. The Duty to Prevent Emotional Harm at Work: Arguments from Science and Law, Implications for Policy and Practice. Bulletin of Science, Technology and Society. August 2004; 24(4): 315-56. http://dx.doi.org/10.1177/0270467604266957

[61] Carr, EG, Dunlap, G, Horner, RHet al. Positive Behavioral Support: Evolution of an Applied Science. Journal of Positive Behavior Interventions. 2002; 4(1): 4-16. http://dx.doi.org/10.1177/109 830070200400102

[62] Spiegelman P, Berrett B. Patients Come Second. Greenleaf Book Group. An Inc. Original. 2013. New York NY.

[63] Danielson, D, Ketterling, R, Rosenstein, A. Physician Stress and Burnout: Causes, Effects, and Impact on Performance and Behavior. AMGA Group Practice Journal. March 2013; 62(3): 38-41. 